\title{
ACADEMIC STRESS AND STUDY HABIT AMONG COLLEGE STUDENTS
}

\author{
Ayisha Thanseera. MK * \\ $2^{\text {nd }}$ year BSc. Psychology Student, \\ Yuvakshetra Institute of Management and \\ Studies, \\ Mundur, Palakkad, \\ Kerala-678631
}

\author{
Nasla. K* \\ $* 2^{\text {nd }}$ year BSc. Psychology Student, \\ Yuvakshetra Institute of Management and \\ Studies, \\ Mundur, Palakkad, \\ Kerala-678631
}

\author{
Sannet Thomas** \\ **Assistant professor, \\ Department of Psychology, \\ Yuvakshetra Institute of Management and Studies, \\ Mundur, Palakkad, \\ Kerala-678631
}

Article DOI: https://doi.org/10.36713/epra6551

\begin{abstract}
Academic stress according to Bisht (2005) academic stress reflects subject's perception as Well as the way of coping with academic events; it reflects subjective feelings of distress or Interpersonal perceptual responses. The term Study habits defined as Study Habits implies a sort of more or less permanent mode or method of Studying. In the present study, Study Habits refers to comprehension, concentration, task Orientation, study sets, interaction, drilling, supports, recording, language etc. as the factors of Study Habits as mentioned by Mukhopadhyaya and Sansanwal (2011) in their Study Habit Inventory. Aim: The study was conducted to find out the relationship between academic stress and Study habits among college students. The sample of the present Study was 40 college students out of which 8 were boys and 32 were girls. Bisht Battery of Stress Scales (revised in 2005) by BishtStudy Habit Inventory (2011) by M.Mukhopadhyay and D.N SansanwalWere used as tools for data collection. Result: The results of the Study shows that there is no significant relationship between academic stress and study habits among college students.
\end{abstract}

KEYWORDS: Study Habits, Academic Stress

\section{INTRODUCTION}

Stress is the term used to describe the physical, emotional, cognitive and behavioral responses. To events that are appraised as threatening or challenging. There are many different types of Stress that students face in college. Most of these are centered on academic issues. Academic Stress among college students has been a topic of interest for many years. Student's experience high stress due to various stressors. When stress is perceived negatively or becomes excessive, it Can affect both health and academic performance (Jasvir Kaur \& Navkiran kaur 2015). Education is a dynamic process. It has continued to evolve, diversify and extend its reach since the dawn of human history. 
Every country develops its own system of education to express and promote its unique socio cultural identity as well as to meet the challenges of the times. Human beings are a precious natural resource. In essence, education is to be looked upon as a unique investment in the present and the future (K.Dhanalakshmi\& k. V. S. N. Murty 2018).

The behaviours and strategies devised and used for preparing for assessments and learning of academic materials are called study habits. Developing good study habits such as having organised routines for homeworks and revisions, proper note preparation techniques etc, are factors that help students to work efficiently and to reduce stress. Study habits of a student refers to his/her potential to schedule, plan, take notes, review etc. An individual's established way of learning, however systematic or unsystematic it may be, can be called his/her study habit.

Students will have to face multiple academic demands such as examinations, graded assignments, competing with peers, comprehending the material taught by the instructor etc. This can lead to frustration due to exhaustion of resources. The mental distress thus caused is called academic stress. Bisht (1989) has defined academic stress as "a demand related to academics that taxes or exceeds the available resources (internal or external) as cognitively appeared by the student involved". According to her academic stress has 4 components, namely academic frustration, academic conflict, academic anxiety and academic pressure.

\section{DEFINITIONS OF THE KEY TERMS}

Academic Stress: According to Bisht (2005) academic stress reflects subject's perception as Well as his way of coping with academic events; it reflects subjective feelings of distress or Interpersonal perceptual responses; at it consists of the components of (a) Frustration (b) Conflicts (c) pressure and (d) anxiety. Scores of the Bisht Battery of stress scale will be taken as Academic stress in the present study.

Study Habits: Study Habits implies a sort of more or less permanent mode or method of Studying. In the present study, Study Habits refers to comprehension, concentration, taskOrientation, studysets, interaction, drilling, supports, recording, language etc. as the factors of Study Habits as mentioned by Mukhopadhyaya and Sansanwal (2011) in their Study Habit Inventory. Here the scores obtained by the student in this inventory are taken as his Study Habits In the present study.

\section{REVIEW OF LITERATURE}

- Kaur,J., \& Kaur, N. :The study was conducted to investigate the significant difference between academic stress and Study habits among adolescents with respect to gender and locale. The sample of the present Study was 200 adolescents. Out of these, 100 were rural adolescents (50 males and 50 females) And 100 were urban adolescents (50 males and 50 females) from Ludhiana district. Bisht Battery of Stress Scales (revised in 2005) by Bisht and Study Habit Inventory (2011) by M.Mukhopadhyay and D.N Sansanwal were used as tools for data collection. The results of the Study showed that there exists significant mean difference of academic stress of male and Female adolescents in regard to their locale at both the levels of significance. There exists no Significant mean difference in academic stress of male and female adolescents at both levels of Significance. It is further observed that mean scores of study habits among female adolescents are more than the mean scores of male adolescents. Mean scores of study habits of adolescents of rural areas are more than the mean scores of adolescents of urban areas.

- Dhanalakshmi, K., \& Murty, K.V.S.N. : study was carried out on $300 \mathrm{~B}$. Ed trainees to find out the effect of study habits and academic Stress of B. Ed trainees. Study Habits inventory developed by Prabhakar and Academic stress scale by Abha Rani Bisht was used to assess the study habits and academic stress of B. Ed trainees. Results revealed that there is a significant impact of study habits and academic stress of B. Ed trainees.

- Rao, K.V.,\& Reddy, S.V.:A study was carried out on 400 teacher trainees to find out the effect of study habits, mental health and academic stress on Academic achievement among teacher trainees. Mental Health Status inventory developed by Reddy, Study Habits inventory Developed by Prabhakar and Scale for Assessing Academic Stress developed by Sinha, Sharma and Mahendra was used to Assess the mental health, study habits and academic stress of the teacher trainees. Results revealed that there is a significant Impact of mental health on study habits and academic stress of prospective teachers. 


\section{METHOD}

\section{Problem}

Is there any significant relationship between academic stress and study habits among college students.

Aim

To understand the relationship between academic stress and study habits among college students.

\section{Objective}

To study the relationship between academic stress and study habits.

\section{Variables}

Dependent variable: academic stress, study habit

\section{Hypothesis}

There will be no significant relationship between the academic stress and study habit among college students.

\section{Research Design}

The research study was quantitative in nature and correlational study was used to determine if there exists a relationship between academic stress and study habits among college students.

\section{Research Sample}

Purposive sampling method was used for this study. The study sample was comprised of 40 college students at age range from 18 to 23 from different parts of Kerala, out of which 8 were males and 32 were females. The sample belongs to different gender religious family type, area of residence.

\section{Sampling Criteria} Inclusion criteria

- Those who have given consent for the participation.

- The samples are around the age of 18 to 23 .

- College Students

\section{Exclusion criteria}

- Those who haven't given consent for the participation.

- Those who have physical disability and mental retardation.
Tools

The following tools were administered to each participant in order to collect the required information.

1. Bisht Battery of Stress Scales (revised in 2005) by Bisht .

2. Study Habit Inventory (2011) by M.Mukhopadhyay and D.N Sansanwal

\section{Procedure}

The purpose of the study has been explained to the participants via online and their willingness to participate in the study ascertained. The first step being that a rapport was established by participants and the researcher through social media, after this each participants were individually educated about the purpose of the study as well as they were informed about the confidentiality of their response. Finally , Bisht Battery of stress scales (Bisht,revised in 2005) of 19 items and study habit Inventory (M.Mukhopadhyay and D.N Sansanwal,2011) of 21 items were given to sample through online with proper instructions one after the other. The scoring of the assessment was done and interpreted according to the manual. The participants were not asked to disclose any of their personal information.

\section{Analysis of data}

The collected data were analysed using following statistical test:

1. Spearman Rank correlation

\section{Ethical issues}

1. Informed consent of each and every participant was acquired.

2. Confidentiality of the response was maintained.

3. The data collected will be solely used for research purpose

\section{RESULTS}

DATA ANALYSIS AND INTERPRETATION:

The aim of the study was to find the relationship between study habit and academic stress among college students. The study consisted of 40 college students out of which 8 were males and 32 were females. For the purpose of study the investigator formulated one hypothesis and results are shown below: 
ISSN (Online): 2455-3662

EPRA International Journal of Multidisciplinary Research (IJMR) - Peer Reviewed Journal Volume: 7 | Issue: 3 | March 2021|| Journal DOI: 10.36713/epra2013 || SJIF Impact Factor 2021:7.147 ||ISI Value: 1.188

Table 1- Spearman's rank correlation between academic stress and study habit among college students.

\begin{tabular}{|cccc|}
\hline & & Study habit & Academic Stress \\
\hline Spearman rho Study habit & Correlation coefficient & 1.000 & -0.31 \\
\hline & Sig. (2 tailed) & - & 0.851 \\
\hline & $\mathrm{N}$ & 40 & 40 \\
\hline Academic Stress & Correlation coefficient & -0.31 & 1.000 \\
\hline & Sig. (2 tailed) & 0.851 & - \\
\hline & $\mathrm{N}$ & 40 & 40 \\
\hline
\end{tabular}

Table 1. shows that, significant value of correlation between academic stress and study habit among college students is 0.851 , which is not significant at 0.05 level of significance. Thus null hypothesis is accepted so there is no significant relationship between academic stress and study habit.

\section{MAJOR FINDINGS}

- There will be no significant relationship between academic stress and study habits among college students.

\section{LIMITATIONS}

- Sample size was small

- Sample was collected only from Kerala

\section{SCOPE FOR FURTHER STUDY}

- Future study can be done in a larger population covering

- More geographical areas and comprising of people related to

- Different categories.

\section{CONCLUSION}

The term 'Study habit' is used to describe a sort of more or less permanent mode or method of studying. In the present study, Study Habits refer to comprehension, concentration, task orientation, study sets, interaction, drilling, supports, recording, language etc. as the factors of Study Habits as mentioned by Mukhopadhyaya and Sansanwal (2011) in their Study Habit Inventory. 'Academic stress' according to Bisht (2005) reflects the subject's perception as well as his way of coping with academic events; it reflects subjective feelings of distress or interpersonal perceptual responses.

The study conducted revealed the relationship between academic stress and study habits among college students. The result of the study shows that there is no significant relationship between academic stress and study habits among college students.

\section{REFERENCE}

1. Kaur,J.,\& Kaur,N.(2015).Study of Academic Stress and Study Habits among Adolescents With Respect To Locale and Gender.

2. Baron, Robert.A.(1995).Psychology.( $3^{\text {rd }}$ ed.),New Delhi Simon \& Schuster Company.

3. Singh,S.(2014). "Study habits in relation to type of school and family "Unpublished M.Ed Dissertation, Panjab University, Chandigarh.

4. Bisht,A.R.(1957). Bisht battery of stress scales, Agra: National Psychological Corporation, KacheriGhat. 